\title{
A Comparative Study of Early Cholecystectomy and Interval Cholecystectomy in Acute Cholecystitis in a Tertiary Care Center.
}

\author{
H.N Singh ${ }^{1}$, Tushar Singh ${ }^{2}$ \\ ${ }^{1}$ Associate Professor, Department Of General Surgery, Nmch, Patna, Bihar, ${ }^{2}$ Senior Resident, Department of General Surgery, IGIMS Patna.
}

\section{Abstract}

Background: The incidence of acute cholecystitis is gradually increasing throughout the world and also in India. 90-95 \% of acute cholecystitis is related to gall stones. Earlier the management of acute cholecystitis was conservative followed by interval cholecystectomy. But in last 25 years, there have been many reports recommending early surgery as a treatment of choice. Subjects and Methods: This study was conducted on 80 patients divided in two groups of 40 each with an idea to study the result of early surgery compared with delayed surgery. Results: Though the mean post-operative stay was almost equal in both groups. The total hospital stay in early surgery was 13.28 days and that in delayed surgery was 21.54 . In early surgery group majority of cases there was no technical difficulty rather good delineation of cystic duct-CBD junction as edema provided a plane of cleavage. In delayed surgery operative difficulties were found in 18 cases due to much adhesion in calot's triangle. Conclusion: So, early surgery was found to be more economical with less hospital stay with minimum morbidity than delayed surgery in acute cholecystitis.

Keywords: Early cholecystectomy, Interval cholecystectomy.

Corresponding Author: Dr Tushar Singh, Senior Resident, Department of General Surgery, IGIMS Patna.

Received: April 2019

Accepted: May 2019

\section{Introduction}

In the last decade, the incidence of gall bladder disease has shown a multi fold increase. More and more cases are diagnosed each year due to proper application of the technologically advanced investigations like ultrasonography and HIDA Scanning. The incidence of acute cholecystitis is gradually increasing throughout the world and also in India.

$90 \%$ to $95 \%$ of cases of acute cholecystitis are related to gall stones representing a complication of cholelithiasis. Acute cholecystitis is a chemical ischaemic inflammation of the gall bladder with bacterial infection as a secondary factor.

Acalculus acute cholecystitis often has fulminant course and frequent complications. It accounts for $5 \%$ to $10 \%$ of acute cholecystitis.

Earlier, the sheet anchor of management of acute cholecystitis was conservative approach with intravenous fluids and analgesia, usually in conjunction with antibiotics. Elective cholecystectomy is carried out after a period of 4-6 weeks when acute attack has settled down. The opinion behind this management was that operation maybe difficult or even dangerous due to gross inflammatory edema and adhesions leading to distortion of the normal anatomy and that the vital structures like common bile duct and the hepatic artery maybe inadvertently injured. It is also thought that a better general condition will withstand the surgery and the operation will be technically easier with less

\section{complication.}

But in last 25 years, there have been many reports recommending early surgery as a treatment of choice and Ganey et al, support this approach with their remarkably low mortality of $0.5 \%$. As now-a-days acute cholecystitis can be diagnosed more easily and specifically with ultrasonography and Scinitigraphy. Ellision (1990) postulates that early operation is technically easier due to cleavage plane form by edema of the gall bladder. Even laparoscopic cholecystectomy indeed can be done safely for patients with acute inflammation of the gall bladder (Maingot's abdominal surgery). Early surgery avoids a waiting period of low grade pain and unpredictable complications with high mortality $(20 \%)$ like generalised peritonitis, empyema, biliary enteric fistula, perforation, gall stone ileus, pancreatitis.

This study was conducted with an idea to study the result of early surgery compared with delayed surgery and find optimum technique for this common and rapidly increasing disease.

\footnotetext{
Aims and Objectives

The present research project is aimed to evaluate the following two groups under study series i.e., patients undergoing Interval cholecystectomy and those undergoing early cholecystectomy for acute cholecystitis with regards to-

1. Per-operative findings and events including operating time and recovery from anaesthesia.
} 
2. Post-operative complications including short term and long term complications of cholecystectomy like bile duct injury, stump blow out, injury to adjacent structures including vascular injury. Intra-abdominal collection of pus or bile, obstructive jaundice etc. and their incidence and outcome.

3. Total duration of hospitalization needed.

4. Cost-effectiveness of individual procedures.

5. Period of convalescence and patient acceptance of their modality

With the above mentioned points in mind, our object is to perform cholecystectomy as soon as possible after confirmation of diagnosis of acute cholecystitis and the patient is in state to perform the surgery, comparing the results with conservative management followed by interval cholecystectomy. The advantage and disadvantages of both the procedures were recorded and analysed statistically to achieve a conclusion. Early cholecyctectomy certainly reduced the patient agonizing periods of attack during the waiting period of elective cholecystectomy in our overcrowded hospitals with reduction of medical and social costs optimal to our economic status.

\section{Subjects and Methods}

This Study was a prospective study carried out in the department of general surgery, Nalanda Medical College and Hospital, Patna, Bihar from April 2016 to September 2017.

The total number of selective Patients in our study was 80 which were divided two group as group A consisting of 40 patients underwent early definite cholecystectomy before 72 hours of admission and group B with remaining 40 patients who underwent planned cholecystectomy for proven gallbladder disease were taken into account for this study.

A detailed history was collected followed by a thorough physical examination including general survey, abdominal examination and other systemic examination.

Selected Patients underwent the base line investigation like-

1. Routine blood examination

2. Blood for sugar, urea and creatinine

3. Liver function test

4. Coagulation profile including prothrombin time.

5. Chest X-ray PA view

6. ECG

7. Straight X-ray abdomen to rule out other acute abdominal conditions

8. Ultrasound of abdomen- in all cases of suspected clinical diagnosis of acute cholecystitis

The patients subjected to Ultrasound went through the standard USG examination for all the signs of acute cholecystitis including ultrasonographic Murphy's sign and other organs were also examined.

\section{Inclusion criteria}

All the patients admitted in surgical OPD and casualty of
$\mathrm{NMCH}$, Patna, Bihar along with some waiting patients of proven gallbladder stones for whom elective cholecystectomy was planned were included in this study series.

\section{Exclusion criteria}

1. Patients having complications of acute cholecystitis like gangrene, emphysematous cholecystitis,perforation and empyema of gallbladder as these are established indications of emergency surgery

2. Patients with co-existing medical disorder like uncontrolled diabetes, uncontrolled hypertension, ischemic heart disease etc.

3. Immunocompromised patients.

4. Patients not given consent for emergency surgery.

All the patients were pre-operatively managed with intravenous fluid as they were restricted to take anything orally. 5\% dextrose solution and Ringer's Lactate solution were run in the ratio of 3:1 according to dehydration status of patients. Other measures were naso-gastric suction through Ryle's tube, antibiotics and supportive measures as anti-emetics H2Blockers, PPI etc.

The operative principles were uniform and all operation done were definitive. The general condition of patients was made stable by fluid, electrolytes corrections. Then the patients were subjected to pre-anaesthetic work up. Cholecystectomy with common bile duct exploration when ever required was done in those who were declared fit for general anaesthesia. The cases presented with features of acute cholecystitis within $24-72$ hours were subjected to early cholecystectomy. The skin incision given in these patients of present study was right sub coastal (Kocher's incision). In our patients, the approach to cholecystectomy was by duct first method, but in some cases it had to be converted to fundus first method if there was severe adhesion in the neck of the gall bladder. Cystic duct and cystic artery were ligated with non absorbable suture material. In three cases common bile duct was explored as pre operative USG showed

I. Stone in bile duct

II. Stone palpated during surgery

III. Bile duct was more than $10 \mathrm{~mm}$ dilated

$\mathrm{T}$-tube drainage was given and T-tube cholangiogram was done on 12thpost operative day. In all cases abdominal drain was placed in hepatorenal pouch. All operation were done within the same hospital admission in the early cholecystectomy surgery group.

The other group had elective cholecystectomy after 4-6 weeks of acute attack; manage conservatively in the first hospital admission.

The bile collected from gall bladder was sent for culture sensitivity. The specimen of gall bladder was sent for cystopathological examination. The details of operations like pre-operative events, post-operative recovery from anaesthesia were noted.

In post-operative management all patient were managed by antibiotics, intravenous fluid for 36-48 hours, analgesic, N$\mathrm{G}$ suction. Drain was removed usually after 48 hours. The patients were discharged on the day following removal of 
stitches.

Follow up: All patients were keenly followed up in surgical OPD after two weeks, Six weeks, and then Six months. Though some patients had irregular follow up.

\section{Results \& Discussion}

Table 1: Age and sex incidence in patients undergoing early and interval cholecystectomy

\begin{tabular}{|l|l|l|l|l|}
\hline Cholecystectomy & $\begin{array}{l}\text { Mean } \\
\text { age } \\
\text { oyear( }\end{array}$ & Sex & $\begin{array}{l}\text { No of } \\
\text { patients }\end{array}$ & Percentage \\
\hline Group-1 & 35.1 & Male & 8 & $20 \%$ \\
& & Female & 32 & $80 \%$ \\
\hline Group-2 & 40.48 & Male & 12 & $30 \%$ \\
& & Female & 28 & $70 \%$ \\
\hline
\end{tabular}

In our study we found that both groups were comparable in terms of demographical variants as distribution of age and sex. The mean age in early surgery group was 35.1 and in interval surgery group it was 40.48 .In both groups females were more affected than males. Findimg of ours is similar to many other studies.

Table 2: Age range of patients undergoing early and interval cholecystectomy

\begin{tabular}{|l|l|l|l|l|}
\hline $\begin{array}{l}\text { AgeGroups } \\
\text { (years) }\end{array}$ & \multicolumn{2}{|l|}{ Group-1 } & \multicolumn{2}{l|}{ Group-2 } \\
\hline & $\begin{array}{l}\text { No of } \\
\text { cases }\end{array}$ & $\begin{array}{l}\text { Percentage } \\
\text { of cases }\end{array}$ & $\begin{array}{l}\text { No } \\
\text { cases }\end{array}$ & $\begin{array}{l}\text { percentage } \\
\text { of cases }\end{array}$ \\
\hline $10-19$ & 3 & $7.5 \%$ & 5 & $12.5 \%$ \\
\hline $20-29$ & 10 & $25 \%$ & 8 & $20 \%$ \\
\hline $30-39$ & 12 & $30 \%$ & 13 & $32.5 \%$ \\
\hline $40-49$ & 6 & $15 \%$ & 10 & $25 \%$ \\
\hline $50-59$ & 4 & $10 \%$ & 2 & $5 \%$ \\
\hline $60-69$ & 3 & $7.5 \%$ & 1 & $2.5 \%$ \\
\hline $70-79$ & 2 & $5 \%$ & 1 & $2.5 \%$ \\
\hline
\end{tabular}

In our study we found that age groups of patients suffering from this disease were almost similar in both groups.
In our study we found that incidence of subtotal cholecystectomy is higher in early surgery group due to difficult adhesion, intra operative haemorrhage and obscure anatomy at the region of junction of cystic and common bile duct. Appendectomy was not performed in any of the group. All cases were preliminary approached by duct first method but in 11 cases of early surgery group had to be converted into fundus first, same was done in 5 cases of interval surgery group. Lahtinen et al (1978) also take the view that it is easier to perform and operation time is significantly shorter in early surgery group.Ellison (1957) also postulated that development of cleavage plain make early surgery easier. In our present series we found in early surgery group it was less difficult to perform surgery than interval surgery group.

Table 3: Details of different operative procedure.

\begin{tabular}{|l|l|l|}
\hline Operative procedure & \multicolumn{1}{|c|}{ Group-1 } & \multicolumn{1}{|c|}{ Group-2 } \\
\hline Cholecystectomy & $19(47.5 \%)$ & $22(55 \%)$ \\
\hline Subtotal cholecystectomy & $5(12.5 \%)$ & 00 \\
\hline $\begin{array}{l}\text { Cholecystectomy+Common bile } \\
\text { duct exploration+T-tube } \\
\text { drainage }\end{array}$ & $5(12.5 \%)$ & $10(25 \%)$ \\
\hline $\begin{array}{l}\text { Cholecystectomy+ } \\
\text { Choledocoduodenostomy }\end{array}$ & 00 & $3(7.5 \%)$ \\
\hline Cholecystectomy+appendectomy & 00 & 00 \\
\hline method 'FundusFirst' & $11(27.5 \%)$ & $5(12.5 \%)$ \\
\hline
\end{tabular}

Table 4: Operating time in early and interval surgery

\begin{tabular}{|l|c|c|c|}
\hline Groups & Type of operation & $\begin{array}{l}\text { No. of } \\
\text { patients }\end{array}$ & $\begin{array}{l}\text { Time for } \\
\text { operation } \\
\text { (Mean } \pm \text { S.D) } \\
\text { in min }\end{array}$ \\
\hline \multirow{2}{*}{ Group-I } & Cholecystectomy & $35(87.5 \%)$ & $72.86 \pm 16.57$ \\
\cline { 2 - 4 } & + Choledocholihotomy & $5(12.5 \%)$ & $98.67 \pm 8.50$ \\
\hline Group-2 & Cholecystectomy & $32(80 \%)$ & $74.95 \pm 12.53$ \\
\cline { 2 - 4 } & + Choledocholithotomy & $8(20 \%)$ & $100.2 \pm 10.11$ \\
\hline
\end{tabular}

The time required during surgery for both early and interval group were almost similar in our study and this was also found in the work of Fowkes and Gunn (1980).

Table 5: Operative difficulties in early and interval surgery groups

\begin{tabular}{|l|l|l|l|l|l|l|}
\hline Groups & $\begin{array}{l}\text { Subtotal } \\
\text { cholecystectomy }\end{array}$ & $\begin{array}{l}\text { Mass ligation of Cystic artery } \\
\text { cystic duct and } \\
\text { artery }\end{array}$ & $\begin{array}{l}\text { Technically } \\
\text { difficult } \\
\text { injury }\end{array}$ & $\begin{array}{l}\text { Haemorrhage in } \\
\text { OT field }\end{array}$ & Total \\
\hline Group-1 & $5(12.5 \%)$ & $5(12.5 \%)$ & 00 & 00 & $5(12.5 \%)$ & $15(37.5 \%)$ \\
\hline Group-2 & 00 & $3(7.5 \%)$ & $2(5 \%)$ & $14(35 \%)$ & 00 & $20(50 \%)$ \\
\hline
\end{tabular}

The operative difficulty faced during cholecystectomy in ES group was to hold the fundus of gall bladder with sponge holding or Moynihan's forceps.Due to friable oedematous wall, it either slipped or a portion of gallbladder wall was partially torn. So, the dissection had to be performed by holding the fundus with a wet mop after aspirating the gallbladder with a syringe and a needle, peritoneal spillage being prevented by mop packing. In 5 cases, subtotal cholecystectomy had to be performed due to obscure anatomy and adhesions in the Calot's triangle. In these 5 cases, fundus first method was applied and after partial removal of gall bladder interrupted sutures with 1-O vicryl were given. In 5 cases, there was operative difficulty due to intra-operative haemorrhage. In one case, inflamed cystic lymph node posed difficulty during tying the cystic duct. In 5 cases mass ligation of cystic artery and cystic duct has to be done. But in majority of cases there was no technical difficulty rather good delineation of cystic duct-common bile duct junction as oedema provided a plan of cleavage.

Table 6: Post-operative complications in both groups

\begin{tabular}{|l|l|l|}
\hline Complications & Group-1 & Group-2 \\
\hline Wound infection & $12(25 \%)$ & $8(20 \%)$ \\
\hline Lung Complications & $6(15 \%)$ & $6) 15 \%)$ \\
\hline Billiary Soakage & $4(10 \%)$ & $3) 7.5(\%$ \\
\hline Pulmonary Embolus & 00 & 00 \\
\hline Pulmonary Edema & 00 & 00 \\
\hline
\end{tabular}

Pulmonary Edema 


\begin{tabular}{|l|l|l|}
\hline Lesions Of CBD & 00 & 00 \\
\hline Lesions Of Duodenum & 00 & 00 \\
\hline $\begin{array}{l}\text { Re-op due to } \\
\text { haemorrhage or bileleak }\end{array}$ & 00 & 00 \\
\hline Stricture & 00 & 00 \\
\hline
\end{tabular}

In group - 2(IS), operative difficulties were found in 20 cases due to much adhesion in the Calot's triangle along with omental attachment. In 3 cases mass ligation of cystic artery was injured during right angled forceps Insertion to separate the cystic duct. It was carefully managed by ligating with 1-0 silk. In 14 cases C.B.D. exploration were done and in 2 cases choledochoduodenostorny has to done. In the comparison of post-operative complications, we found wound infection to be common of all the complications and it has got a slight greater incident in early surgery group. This corroborates with the findings of Payne (1969), Linden and Sanzel (1979), Macarthur et al (1975) and Morrow et al (1978). Another interesting feature of early operations is that post operative morbidity is less compared to interval surgery. This was noted by Jarvinen and Hastbacka (13.8\% vs. $17.3 \%)$. The overall post operative complications rate is almost equal in both the groups.

Table 7: Mean hospital stay both groups (indays)

\begin{tabular}{|l|l|l|l|}
\hline Groups & Pre-Operative & $\begin{array}{l}\text { Post- } \\
\text { Operative }\end{array}$ & Total \\
\hline Group-1(ES) & 1.44 & 10.28 & 13.28 \\
\hline Group-2(IS) & 9.24 & 12.04 & 21.64 \\
\hline
\end{tabular}

Though the mean post- operative stay was almost equal in both the Groups, the great difference was found in the total hospital stay. The total hospital stay of group-1(ES) in our series was 13.28 days and that of IS group was 21.64 days. So, 8.36 days are saved if early surgery is undertaken. To this is added another 2.5 days as average time spent during non- operating stay in our series. Bhaumik et al, in their study found that early operation group had mean postoperative stay of $15.46 \pm 5.38$ days.Norrby et al., (1983) found that the average time spent in hospital during nonoperative stay was 7.2 days. In their series, the mean postoperative stay was exactly the same (6.6 days) but the difference was found in the total hospital stay, being 6.4 days shorter in the ES group. They had total hospital stay in ES group of 9.1 days and that of DS group was 15.5 days. Addison and Finan (1988) found that the number of days between operation and discharge to be approximately the same (elective 12.8, early 13.6). This agrees with the work of other who claims that there is no increase in the number of days from operation to discharge in the early group compared with the delayed group and the former therefore is more cost-effective.

So far, the cost of total treatment is concerned the patients treated by early surgery had the benefit of not Paying double charges or medicinal costs like antibiotics. Moreover, there was less wastage of days in comparison to delayed surgery, as many patients could not be admitted in due time for planned surgery and they had to come to outpatient department many times before admission.
In follow up, only one patient from the early surgery group did suffer from medical jaundice with positive surface antigen. Other patients of early surgery group and all patients of delayed surgery group had no complaints in follow up study excepting minor problems like pain In the incision line and infection at the drainage site.

So early surgery is found to be more economical with less hospital stay with minimum morbidity than delayed surgery in acute cholecystitis. If diagnosis can be confirmed in proper time.

\section{Conclusion}

The definitive treatment of acute cholecystitis is cholecystectomy. The timing of operation was debated until recently when data from several studies became available. According to some, patients should be treated conservatively, allowing resolution of the acute inflammation followed by elective cholecystectomy approximately six weeks later. Other claims that operation should be done as soon as diagnosis is made.

However, our present study found that early operation may become a corner stone in the treatment of acute cholecystitis as the cost effectiveness of early surgery and early return to productivity is optimum to the economic infrastructure of our population. We also found the prolonged waiting period in our already overcrowded hospitals and also non availability of beds in due time plan for elective surgery make it more cumbersome for patients. And added to this problem there is another group of patients who did not report in due time for elective surgery and reported very late with further medical and surgical complications.

The significant findings in our study was the mortality in early and interval surgical therapy were equal and no significant difference was found in frequency or severity of post-operative complications in both groups. But there is significant difference in operative difficulty; total hospital stay, post-operative morbidity and all the above points favour early operation.

So, to conclude early surgery is recommended in acute cholecystitis after a brief period of assessment and preparation for operation with intravenous fluids, nasogastric suction and antibiotics but a larger number of population needs to be evaluated for a satisfactory surgical methods as number of patients in our study is not up to mark and in delayed surgery group, patients were not treated with uniform protocol and referred from different centres also.

\section{References}

1. Ganey J.B, Johnson P.A (Jr), Prillaman P.E. et al: Cholecystectomy Clinical Experience with a Large Series. Am.J.Surg. 151, 3521986

2. Ellison E.H: Early Operation for Acute Cholecystitis in "Current Surgical Management" (Editors Mulholland J.H, Ellison EJ-1 and Friesen S.R Philadelphia, Saunders 1957. Quoted from American journal of Surgery 120: 7, 1990.

3. Jarvinen HJ, Hastbacka J. Early cholecystectomy for acute cholecystitis. Am Surg 1980; 191: 50 1-505.

4. 32. Morrow D.J, Thompson J and Wilson S.E: Acute Cholecystitis In 
elderly: A surgical Emergency. Archives of Surgery, 133: 1149, 1978.

5. Mc Arthur P, Cuschleri A, Sells RA and Shields R: Controlled CitniocalTrial Comparing Early with Interval Cholecystectomy for Acute Cholecystitis. British Journal of Surgery 62: 850, 1975.

6. Klingensmith W, Walkings W and Oles P: Cholecystectomy in Acute Cholecystitis. Archives of Surgery 92: 689, 1966.

7. Payne R.A: Evaluation of the Management of Acute Cholecystitis.British Journal of Surgery 56: 200, 1969.

8. Linden W.V and Sanzel H: Early versus delayed operation for Acute Cholecystitis. American Journal of Surgery 120: 7, 1970.

9. Braasch J.W. Wheeler W, M and Coicock HP: Acute Cholecystitis.Surgical Clinics of North Arneilca. 44: 707, 1969.

10. Byrne J.J: Acute Cholecystitis. American Journal of Surgery 97: 156, 1959.
11. Carmeron IC. Chadwick C, Phillips J, et al. Acute cholecystitis room for Improvement? Ann R Coil SurgEngi 2002; 84: 10-13. [Medline].

12. Cheruvu CVN, Eyre Brook IA. Consequences of prolonged wait before Gallbladder surgery. Ann R Coil SurgEngi 2002; 84: 20-2. [Medline].

13. Cole W.H: Recent Trend in Gallbladder Surgery. J.A.MA.150: 631.1952.

14. Fowkes F.G.R and Gunn A.A: Management of acute cholecystitis and its hospital cost. British Journal of surgery 67: 613, 1980.

15. BhaumikN, Pal R, and Konark S.R: Indian journal of surgery. 44; 75, 1982.

Copyright: (C) the author(s), 2019. It is an open-access article distributed under the terms of the Creative Commons Attribution License (CC BY 4.0), which permits authors to retain ownership of the copyright for their content, and allow anyone to download, reuse, reprint, modify, distribute and/or copy the content as long as the original authors and source are cited.

How to cite this article: Singh HN, Singh T. A Comparative Study of Early Cholecystectomy and Interval Cholecystectomy in Acute Cholecystitis in a Tertiary Care Center. Asian J. Med. Res. 2019;8(2):SG06-SG10.

DOI: dx.doi.org/10.21276/ajmr.2019.8.2.SG2 